\title{
Tunable water-based lubrication behavior of alkyl- and fluoroalkyl-silanes
}

\author{
LIU YuHong*, LIU PengXiao \& XIAO YuQi \\ State Key Laboratory of Tribology, Tsinghua University, Beijing 100084, China
}

Received October 11, 2011; accepted January 18, 2012

\begin{abstract}
In this paper, we report the tribological properties of self-assembled molecular (SAM) films of fluoroalkylsilanes and non-fluoroalkylsilanes, with different chain-lengths, adsorbed on Si substrate surfaces by covalent bonds. The SAM films were characterized using a universal ball-disk experimental tester in aqueous solutions. The substrate surface was examined by X-ray photoelectron spectroscopy (XPS), and the SAM films adsorbed on the Si surfaces were inspected by contact angle measurements and XPS. Lubrication studies revealed that several kinds of fluoroalkylsilanes had similar friction coefficients; the small differences were attributed to the chain flexibility. In contrast, differences in the aqueous lubrication properties of SAM films of non-fluoroalkylsilanes were clearly identified. It is suggested that substitution with fluorine atoms and the surface affinities of fluoroalkylsilanes contributed to redistribution of surface changes, causing variations in lubrication behaviors.
\end{abstract}

water-based lubrication, wettability, self-assmebled molecular films

Citation: $\quad$ Liu Y H, Liu P X, Xiao Y Q. Tunable water-based lubrication behavior of alkyl- and fluoroalkyl-silanes. Chin Sci Bull, 2012, 57: 1879-1885, doi: $10.1007 / \mathrm{s} 11434-012-5106-2$

Friction is a common phenomenon in engineering, and much energy is wasted because of serious friction or wear between moving parts. Much effort has been devoted to controlling energy dissipation during surface interactions. Also, micro/nano-electromechanical systems (MEMS/ NEMS), the use of which has increased in recent decades, have many other tribological problems [1-4]. As the dimensions of a system decrease, the surface area/volume ratio increases. This could cause surface forces such as adhesion and friction to predominate over inertial forces [5]. Tribological limitations such as stiction, friction, and wear are major problems that limit the efficiency, power output, and reliability of these devices [6-8].

Although Si is the material most used in MEMS/NEMS components, the tribological performance of $\mathrm{Si}$ is very poor . Nanometer-thick organic self-assembled molecular (SAM) films are potential candidates as lubricants for improving the performance of MEMS and NEMS. Recently, much attention has been paid to self-assembled monolayers be-

*Corresponding author (email: liuyuhong@tsinghua.edu.cn) cause they are easy to prepare, and they have excellent properties such as low thickness, stable physical and chemical properties, and good covalent bonding with substrates [9]. Moreover, the properties of SAM films can be extended by changing the lengths of the molecules, the type of terminal group, and the degree of cross-linking within the layer. In particular, fluorinated organic thin-films have been much studied because of their unique chemical stabilities and anti-adhesive properties [10-12]. Organosilane ultrathin films have been identified as promising boundary lubricants. This is because organosilane molecules interact strongly with substrates and their thicknesses are commensurate with the dimensions of the structures in these applications [13]. The introduction of fluorine could lead to enhanced intra- and inter-molecular steric interactions for bulky CF3-terminated films, and the corresponding lateral steric interactions can plausibly occur over distances sufficiently long to permit the propagation of surface phonons [14]. These properties make them good candidates for use in micro/nano devices. Alkylsilane SAM films have therefore been extensively studied, and proposed as lubricants for MEMS [15-18]. It is 
known that roughness has a significant effect on the friction characteristics of solid surfaces [19-21]. Moreover, nanometer-thick films of organic self-assembled molecules, which have been used to modify the chemical nature of surfaces, have been shown to be good lubricants for improving the tribology of MEMS/NEMS devices [22].

Considering the hydrophobic properties of decorated surfaces and their interactions with water molecules, the aim of our present work is to study the tribological properties of SAM films, made using a series of alkylsilanes with different chain-lengths and fluorinated substituents on the surface of the Si wafers, under water lubrication conditions. This is different from our previous work [23,24], in which SAM films were investigated without any lubricants. The frictional characteristics of SAM films and their hydrophobicities can be studied with high reproducibility. The experimental results for perfluoroalkylsilane and non-perfluoroalkylsilane molecular films were compared in detail. The influences of the sliding velocity, the normal load, and the carbon-chain length of the alkylsilane molecular film on the friction coefficient were also evaluated. All the results showed that alkylsilane SAM films have great potential in technology and engineering applications.

\section{Experimental}

\subsection{Materials}

A single-crystal p-type Si (100) substrate (GRINM Semiconductor Materials Co., Ltd.) was used as received without further rinsing. Octyltrichlorosilane (denoted as C8, purity 97\%) and decyltrichlorosilane (denoted as $\mathrm{C} 10$, purity 97\%) were obtained from Acros Organics and Aldrich, respectively, and used without any further purification. $1 \mathrm{H}, 1 \mathrm{H}, 2 \mathrm{H}$, 2H-Perfluorooctyltrichlorosilane (denoted as $\mathrm{C} 8 \mathrm{~F}$, purity $97 \%$ ) and $1 \mathrm{H}, 1 \mathrm{H}, 2 \mathrm{H}, 2 \mathrm{H}$-perfluorodecyltrichlorosilane (denoted as $\mathrm{C} 10 \mathrm{~F}$, purity 96\%) were purchased from ABCR $\mathrm{GmbH} \& \mathrm{Co}$. and Lancaster Synthesis, respectively. Chloroform, hydrofluoric acid, ammonia, vitriol, hydrogen peroxide, and toluene were bought from Beijing Jinxin Chemical Factory (AR grade). All solutions were prepared with Millipore (Milli-Q) water.

\subsection{Substrate preparation}

A single-crystal p-type $\mathrm{Si}$ (100) Si wafer polished on one side was cut into pieces of approximately $1.5 \mathrm{~cm}$ by $1.5 \mathrm{~cm}$ before cleaning and modification. The wafers were first cleaned by the following procedure: (1) ultrasonic degreasing in chloroform, acetone, and ethanol for $5 \mathrm{~min}$ each, followed each time by $10 \mathrm{~min}$ of supersonic rinsing in distilled water to remove any possible contaminants; (2) etching in hydrofluoric acid $(40 \%)$ at room temperature for $30 \mathrm{~s}$ to remove the natural oxide layer; (3) cleaning and oxidizing by heating at $90^{\circ} \mathrm{C}$ in piranha solution $\left(98 \% \mathrm{H}_{2} \mathrm{SO}_{4}: \mathrm{H}_{2} \mathrm{O}_{2}=\right.$
$7: 3, v / v)$ for $30 \mathrm{~min}$. The wafers were rinsed with water between each step. The cleaned wafers were immediately transferred to a cyclohexane (chromatographic purity) solution of octyltrichlorosilane (or another silane) with a volume ratio of 1:500 and incubated for $15 \mathrm{~h}$ to allow formation of molecular films. The wafers were then immersed in each of cyclohexane, acetone, and ethanol, and thoroughly supersonically rinsed to remove unbound silanes. The solvent was completely vaporized using high-purity nitrogen gas, to give a Si (100) substrate covered with the assembled molecules. Chemical adsorption of the $\mathrm{Si}-\mathrm{O}$ covalent bond resulted in single-crystal $\mathrm{Si}$ wafer substrates modified by self-assembled alkylsilanes; this is shown schematically in Figure 1.

\subsection{Apparatus and measurements}

The bare Si wafer and the Si wafer decorated with molecular films of trichlorosilanes were characterized by X-ray photoelectron spectroscopy (XPS) to confirm the existence of SAM films on the Si substrates. The experiments were carried out using a PHI Quantera (ULVAC-PHI, Inc.) scanning X-ray microprobe. A monochromated $\mathrm{Al} \mathrm{K \alpha}$ line $(1486.7 \mathrm{eV})$ was used as the excitation source. The binding energy was calibrated against the $\mathrm{C} 1 \mathrm{~s}$ peak of the carbon contaminant at $284.8 \mathrm{eV}$.

The contact angles of the surfaces with trichlorosilane molecular films were measured with a JC2000A (Shanghai, China; precision: $\pm 0.1^{\circ}$ ) under ambient conditions. Water droplets $(2 \mu \mathrm{L})$ were dripped carefully onto the surfaces of the molecular film and the Si wafer. The average contact angle was obtained by measuring three different positions of the same sample.

The thicknesses of the alkylsilane molecular films were measured using a Multiskop ellipsometer (Optrel GBR; $a=$ $532 \mathrm{~nm}$, angle of incidence $=70^{\circ}$ ). The thicknesses of the C8 and C10 alkylsilane molecular films were calculated using refractive indexes of 1.447 and 1.452, respectively; the results were $1.0 \mathrm{~nm}$ and $1.2 \mathrm{~nm} \mathrm{[25]} \mathrm{(Table} \mathrm{2),} \mathrm{which} \mathrm{is}$ consistent with the tilt from the surface normal expected in these systems. Each reported value is the average of at least

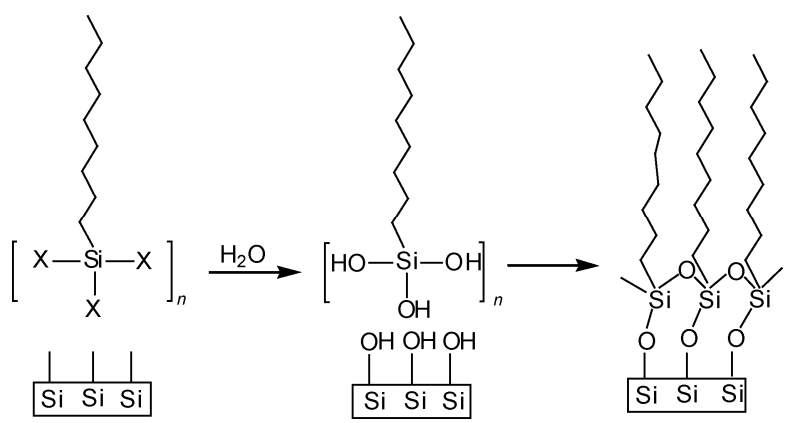

Figure 1 Schematic diagram of the mechanism of trichlorosilane assembly on a single-crystal $\mathrm{Si}$ wafer. 
15 measurements obtained from the samples.

Tribological experiments were conducted in an ambient atmosphere in aqueous solutions at a temperature of about $28^{\circ} \mathrm{C}$ and a relative humidity of $35 \%$. The amount of water used as a lubricant was $50 \mu \mathrm{L}$. A ball-on-disk universal microtribometer (UMT-2, CETR, rotary style) was used to evaluate the frictional properties of the prepared samples. An $\mathrm{Si}_{3} \mathrm{~N}_{4}$ ball was fixed at the top of the pin on the tribometer's counterpart in these experiments. The diameter of the ball was about $4 \mathrm{~mm}$, and its surface roughness ( $\mathrm{Ra}$ ) was approximately $14 \mathrm{~nm}$. The normal load was used in the range $0.8-3 \mathrm{~N}$. The friction force curves and the coefficient of friction versus time were measured and recorded simultaneously.

\section{Results and discussions}

Parallel XPS experiments were performed to characterize the Si wafer surface and the SAM films on the Si substrate, as shown in Figure 2. Table 1 summarizes details of the binding energies and chemical compositions. It can be seen that the cleaned $\mathrm{Si}$ wafer had prominent $\mathrm{O} 1 \mathrm{~s}$ and $\mathrm{Si} 2 \mathrm{p}$ peaks, which indicated that hydroxyl groups were also present in the substrate. The low-intensity $\mathrm{C} 1 \mathrm{~s}$ (the binding energy is about $284 \mathrm{eV}$ ) peak in the XPS spectrum of the Si surface is probably caused by organic contaminants adsorbed from the atmosphere during specimen preparation for the XPS measurements. The photoemission intensity of the $\mathrm{C} 1 \mathrm{~s}$ peak from the organic contaminant is considerably lower than those of the alkylsilane-modified surfaces. As a result of the adsorption of alkylsilane molecules, the binding energy of the $\mathrm{C} 1 \mathrm{~s}$ peak $(283 \mathrm{eV}$ ) in the $\mathrm{C} 8 / \mathrm{Si}$ and $\mathrm{C} 10 / \mathrm{Si}$ spectra is different from that of the peak arising from the carbon contaminant $(284 \mathrm{eV})$. According to the standard test data for XPS, the $\mathrm{C} 1 \mathrm{~s}$ peak at about $283 \mathrm{eV}$ is attributed to the carbon atoms of the methylene group in non-fluorinated alkylsilanes. The differences between the photoemission intensities and the binding energies of the bare Si surface and surfaces decorated with alkylsilane molecules confirm successful deposition of $\mathrm{C} 8$ and $\mathrm{C} 10$. The high atomic concentration of $\mathrm{F} 1 \mathrm{~s}$ (binding energy: $688 \mathrm{eV}$ ) in the spectra of $\mathrm{C} 8 \mathrm{~F} / \mathrm{Si}$ and $\mathrm{C} 10 \mathrm{~F} / \mathrm{Si}$ confirms the formation of $\mathrm{C} 8 \mathrm{~F}$ and $\mathrm{C} 10 \mathrm{~F}$ on the $\mathrm{Si}$ wafers.

The results of water contact angle measurements on the surfaces of bare $\mathrm{Si}$ and on Si modified with alkylsilane molecular films are shown in Figure 3. The images in Figure 3 show the static water contact angle with a water droplet $(2 \mu \mathrm{L})$. The contact angles of $\mathrm{Si}, \mathrm{C} 8 / \mathrm{Si}, \mathrm{C} 10 / \mathrm{Si}, \mathrm{C} 8 \mathrm{~F} / \mathrm{Si}$, and $\mathrm{C} 10 \mathrm{~F} / \mathrm{Si}$ were $67^{\circ}, 111^{\circ}, 114^{\circ}, 119^{\circ}$, and $128^{\circ}$, respectively. For ease of comparison, all the data on the water contact angle of the bare Si substrate and those of substrates decorated with alkylsilane molecular films are summarized in Table 2. Obviously, bare $\mathrm{Si}$ is relatively hydrophilic and modification by fluorinated and non-fluorinated silane
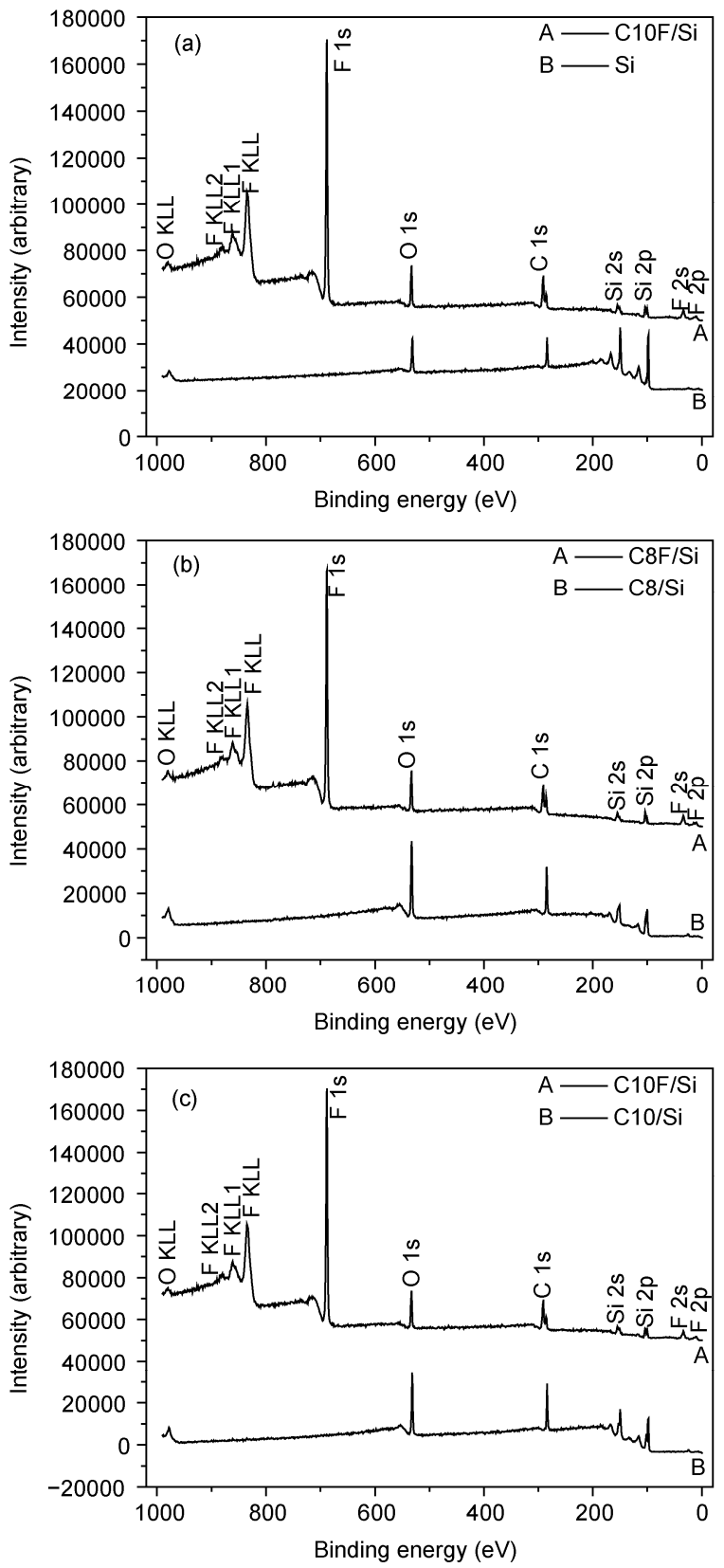

Figure 2 XPS spectra of bare $\mathrm{Si}$ and $\mathrm{Si}$ surfaces modified with fluoroalkyl- and non-fluoroalkyl-silane molecules: (a) bare $\mathrm{Si}$ and C10F/Si, (b) $\mathrm{C} 8 / \mathrm{Si}$ and $\mathrm{C} 8 \mathrm{~F} / \mathrm{Si}$, and (c) $\mathrm{C} 10 / \mathrm{Si}$ and $\mathrm{C} 10 \mathrm{~F} / \mathrm{Si}$. The $\mathrm{C} 8 \mathrm{~F} / \mathrm{Si}$ and $\mathrm{C} 10 \mathrm{~F} / \mathrm{Si}$ spectra were shifted up by 50000 units in parallel.

Table 1 XPS binding energies $(\mathrm{EB} \pm 0.02 \mathrm{eV})$ of the different peak components $^{\text {a) }}$

\begin{tabular}{lcrrr}
\hline & Si2p & \multicolumn{1}{c}{ C1s } & O1s & \multicolumn{1}{c}{ F1s } \\
\cline { 2 - 5 } & B.E $(\mathrm{eV})$ & B.E $(\mathrm{eV})$ & B.E $(\mathrm{eV})$ & B.E(eV) \\
\hline $\mathrm{Si}$ & 98 & 284 & 557 & \\
$\mathrm{C} 8$ & 98 & 283 & 555 & \\
$\mathrm{C} 10$ & 98 & 283 & 553 & \\
$\mathrm{C} 8 \mathrm{~F}$ & 104 & 286 & 555 & 688 \\
$\mathrm{C} 10 \mathrm{~F}$ & 100 & 286 & 557 & 688 \\
\hline
\end{tabular}

a) B.E: Binding energy. 

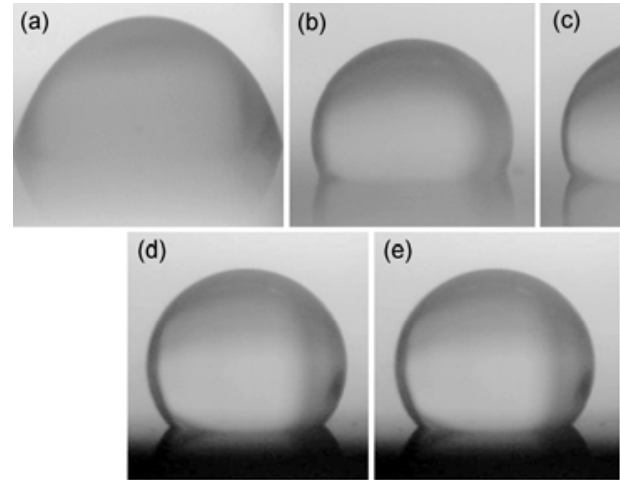

Figure 3 Images of water droplet (volume: $2 \mu \mathrm{L}$ ) on the surfaces of (a) bare $\mathrm{Si}$, (b) $\mathrm{C} 8 / \mathrm{Si}$, (c) $\mathrm{C} 10 / \mathrm{Si}$, (d) $\mathrm{C} 8 \mathrm{~F} / \mathrm{Si}$, and (e) $\mathrm{C} 10 \mathrm{~F} / \mathrm{Si}$.

Table 2 Contact angles and thicknesses of the self-assembled molecular films

\begin{tabular}{lcc}
\hline Samples & Contact angle & Thickness $(\mathrm{nm})$ \\
\hline $\mathrm{Si}$ & $67^{\circ}$ & \\
$\mathrm{C} 8 / \mathrm{Si}$ & $111^{\circ}$ & 1.0 \\
$\mathrm{C} 10 / \mathrm{Si}$ & $114^{\circ}$ & 1.2 \\
$\mathrm{C} 8 \mathrm{~F} / \mathrm{Si}$ & $119^{\circ}$ & 2.8 \\
$\mathrm{C} 10 \mathrm{~F} / \mathrm{Si}$ & $128^{\circ}$ & 4.3 \\
\hline
\end{tabular}

molecules could significantly improve the hydrophobicity of the bare Si substrate. The larger water contact angles of $\mathrm{C} 8 \mathrm{~F}$ and $\mathrm{C} 10 \mathrm{~F}$ adsorbed on the bare Si substrate compared with those of $\mathrm{C} 8$ and $\mathrm{C} 10$ adsorbed on the bare Si substrate may be caused by fluorination of the methyl and methylene groups, leading to lower surface energies of $\mathrm{C} 8 \mathrm{~F}$ and $\mathrm{C} 10 \mathrm{~F}$. As a result, the electrical affinity increased significantly for perfluorinated substitution [26]. This means that the ability of fluorosilanes to accept electrons is stronger than that of non-fluorinated silanes. Furthermore, the substitution of fluorine atoms could enhance the Van der Waals interactions between the silane molecular chains, resulting in better ordering of the SAM films; this improves the hydrophobicity of the SAM films. A comparison of the water contact angles of $\mathrm{C} 8 \mathrm{~F}$ and $\mathrm{C} 10 \mathrm{~F}$ molecular films decorated on the $\mathrm{Si}$ substrate (Table 2) shows that the carbon-chain length has a slight effect on the static contact angles; in other words, the longer carbon-chain of $\mathrm{C} 10 \mathrm{~F}$ molecules results in excellent hydrophobicity because of the stronger interactions between the carbon chains of the $\mathrm{C} 10 \mathrm{~F}$ molecules than between those of the $\mathrm{C} 8 \mathrm{~F}$ molecules.

The thicknesses of the alkylsilane molecular films were investigated using a Multiskop ellipsometer. The thicknesses of the $\mathrm{C} 8, \mathrm{C} 10, \mathrm{C} 8 \mathrm{~F}$, and $\mathrm{C} 10 \mathrm{~F}$ films are $1.0 \mathrm{~nm}, 1.2 \mathrm{~nm}$, $2.8 \mathrm{~nm}$, and $4.3 \mathrm{~nm}$, as is shown in Table 2. It can be concluded from the data that the $\mathrm{C} 8$ and $\mathrm{C} 10$ molecular films are monolayers and the $\mathrm{C} 8 \mathrm{~F}$ and $\mathrm{C} 10 \mathrm{~F}$ are not monolayers, based on the lengths of the molecules. The monolayer film thicknesses of the $\mathrm{C} 8$ and $\mathrm{C} 10$ films were estimated based on the $\mathrm{C}-\mathrm{C}$ bond length $(0.154 \mathrm{~nm})$ in saturated alkanes.
The calculated results for $\mathrm{C} 8$ and $\mathrm{C} 10$ were about $1.078 \mathrm{~nm}$ and $1.386 \mathrm{~nm}$, respectively; these values correspond to our experimental results for non-fluorinated silane molecules. The formation of multilayer films of $\mathrm{C} 8 \mathrm{~F}$ and $\mathrm{C} 10 \mathrm{~F}$ on the substrates is attributed to hydrolysis of $\mathrm{C} 8 \mathrm{~F}$ and $\mathrm{C} 10 \mathrm{~F}$; this means that two or three fluorinated alkylsilane molecules first cross-linked with each other, and then covalently bonded to the Si substrate. As is known, the fluorination of alkylsilanes increases the polarity of the $\mathrm{Si}-\mathrm{Cl}$ bond as a result of their electrical affinities, and this makes hydrolysis of $\mathrm{C} 8 \mathrm{~F}$ and $\mathrm{C} 10 \mathrm{~F}$ molecules easier.

For further investigation of the tribological properties of the bare Si substrate and the surfaces modified with SAM films of fluorinated and non-fluorinated alkylsilanes with different chain-lengths, variations in the curves of friction coefficients versus time in the sliding-velocity range 3-120 $\mathrm{mm} / \mathrm{s}$ were measured using water as a lubricant, as shown in Figure 4.

Repeated measurements on independently prepared samples produced similar results. The friction coefficients of the Si substrate and of the substrate modified by fluorinated and non-fluorinated alkylsilane increase with increasing sliding-velocity after the running period, although this effect is not obvious at low sliding-velocities; this is a result of enhancement of the sheer force during the friction process. It can be seen from Figure 4(a) that the friction coefficients of bare Si under conditions of aqueous lubrication are much lower than that under dry conditions, which is about 0.7 , as shown in our previous experiments [23]. In contrast to the results of the friction experiments performed in the dry state, it can be observed that all four alkylsilane SAM films sustain a higher sliding-velocity under conditions of aqueous lubrication. When the sliding velocity reached 200 $\mathrm{mm} / \mathrm{s}$, only C8/Si (Figure 4(b)) and C10/Si (Figure 4(c)) were destroyed after a sliding time of $200 \mathrm{~s}$. These results could be attributed to lubrication by water. In these experiments, the amount of water used as a lubricant was $50 \mu \mathrm{L}$, and the water formed a thin film around the $\mathrm{Si}_{3} \mathrm{~N}_{4}$ ball during the sliding process after the running period; this can be regarded as thin-film lubrication. It is also seen that the friction coefficients of $\mathrm{Si}$ modified with self-assembled alkylsilane molecules are lower than those of the bare $\mathrm{Si}$ at the same sliding velocity conditions, when the SAM films were not damaged. Comparing the friction coefficients of $\mathrm{C} 8 / \mathrm{Si}$ and $\mathrm{C} 10 / \mathrm{Si}$ in Figure 4(b) and (c) with those of $\mathrm{C} 8 \mathrm{~F} / \mathrm{Si}$ or $\mathrm{C} 10 \mathrm{~F} / \mathrm{Si}$ in Figure 4(d) and (e), it is shown that $\mathrm{C} 8 \mathrm{~F} / \mathrm{Si}$ and $\mathrm{C} 10 \mathrm{~F} / \mathrm{Si}$ are less sensitive to variations in the sliding velocity, and more durable at higher slidingvelocities because the SAM films of fluorine-substituted alkylsilanes are very stable and ordered. This result is the same as that in our previous work [23,24], and could be explained as follows. In aqueous solutions, perfluorocarbon chains adopt a helical conformation and consequently possess larger cross-sections than those of simple hydrocarbon chains, resulting in a strong ability to endure 

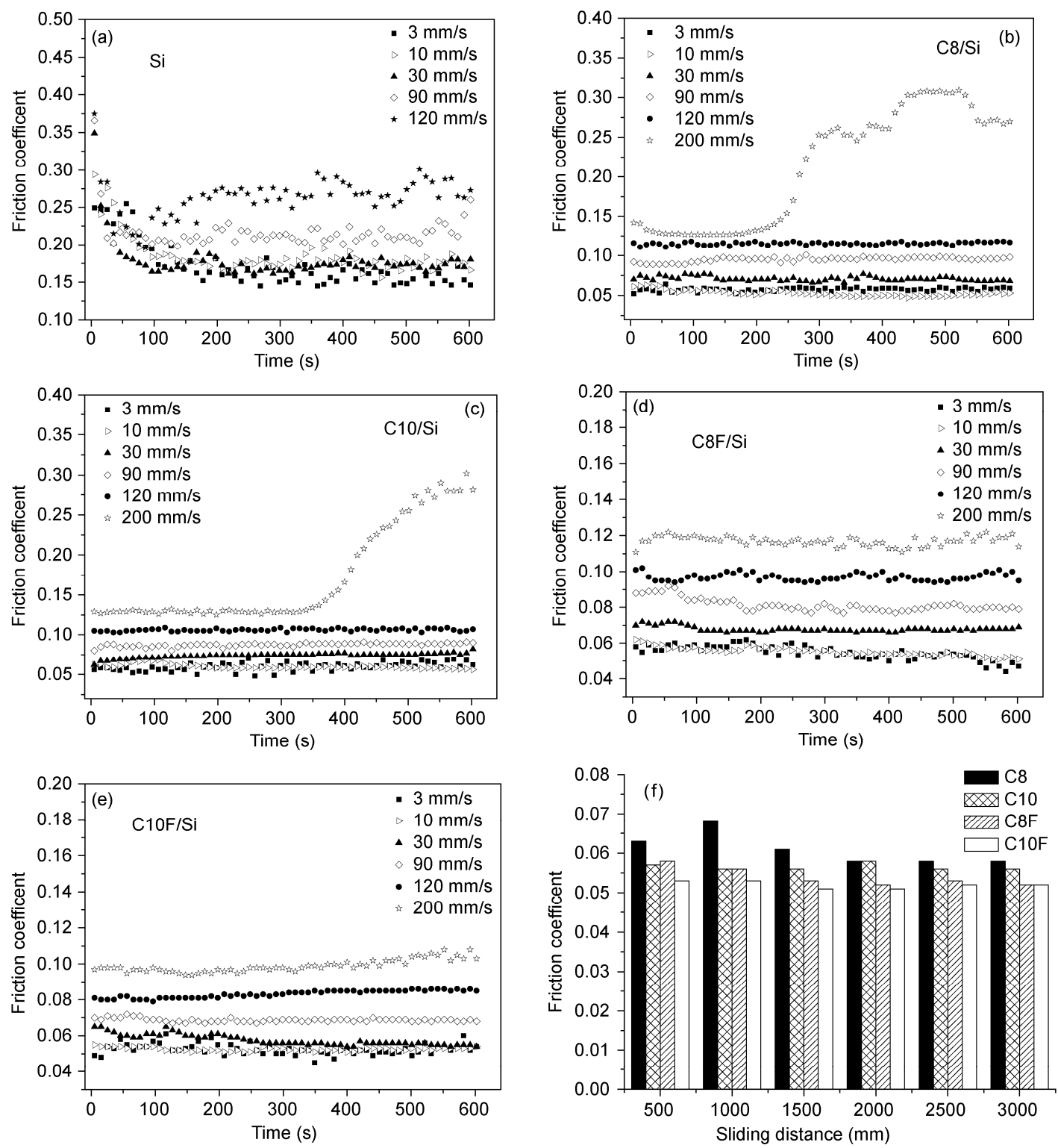

Figure 4 Variations in the friction coefficients over time at load of $80 \mathrm{~g}$ for a steel ball sliding against (a) $\mathrm{Si}$, (b) C8/Si, (c) C10/Si, (d) C8F/Si, (e) C10F/Si, and (f) $\mathrm{C} 8 / \mathrm{Si}, \mathrm{C} 10 / \mathrm{Si}, \mathrm{C} 8 \mathrm{~F} / \mathrm{Si}, \mathrm{C} 10 \mathrm{~F} / \mathrm{Si}$ at a sliding velocity of $10 \mathrm{~mm} / \mathrm{s}$, under water lubrication conditions.

high sliding-velocities, even though the perfluorocarbon chains are more rigid than hydrocarbon chains, and high resistance to oxidation and corrosion [27]. Another important phenomenon to note is that the differences between the friction coefficients of $\mathrm{C} 8 / \mathrm{Si}$ and $\mathrm{C} 10 / \mathrm{Si}$ and those of $\mathrm{C} 8 \mathrm{~F} / \mathrm{Si}$ and $\mathrm{C} 10 \mathrm{~F} / \mathrm{Si}$, i.e., between hydrocarbon chains and perfluorocarbon chains, are much smaller than those we observed in the dry-state experiments. This may be caused by interactions between the water molecules and the carbon chains, which would reduce the differences between the conformations of the perfluorocarbon chains and the hydrocarbon chains. For ease of comparison, the friction coefficients of the $\mathrm{C} 8 / \mathrm{Si}, \mathrm{C} 10 / \mathrm{Si}, \mathrm{C} 8 \mathrm{~F} / \mathrm{Si}$, and $\mathrm{C} 10 \mathrm{~F} / \mathrm{Si}$ surfaces at a sliding velocity of $10 \mathrm{~mm} / \mathrm{s}$ are summarized in Figure 4(f). It can be seen that the friction coefficients de- creased as the hydrophobicities of the alkylsilane SAM films increased. We therefore know that the wettability has an influence on the tribological properties of the surfaces, i.e., the more hydrophobic the surfaces are, the lower the friction coefficients are. A possible reason could be adhesion. As we mentioned above, the much more hydrophobic $\mathrm{C} 8 \mathrm{~F}$ and $\mathrm{C} 10 \mathrm{~F}$ have lower surface energies, as the contact angle measurements show, so the adhesion force between $\mathrm{C} 8 \mathrm{~F} / \mathrm{C} 10 \mathrm{~F}$ and the steel ball should be less than that between $\mathrm{C} 8 / \mathrm{C} 10$ and the steel ball [28], leading to lower friction. The carbon-chain lengths of the alkylsilane molecular films also have a slight effect on the friction coefficient. It has been shown that the adhesion force decreases with increasing chain-length [29], therefore the friction of $\mathrm{C} 10 \mathrm{~F} / \mathrm{Si}$ is lower than that of $\mathrm{C} 8 \mathrm{~F} / \mathrm{Si}$. 
As well as investigating the effects of sliding velocity on the friction coefficients, we also studied the influence of a normal load on the tribological properties of alkylsilane SAM films at a sliding velocity of $10 \mathrm{~mm} / \mathrm{s}$, as shown in Figure 5. It is clear that as the normal load increases, the friction coefficients increase accordingly. This is the same as the findings of our previous work [23]. The difference between the results for dry-state experiments and those with aqueous lubrication is that before the normal load reached $300 \mathrm{~g}$, the four alkylsilane SAM films showed good pressure resistance because the thin water-film around the steel ball effectively reduces the friction coefficient. It was also confirmed that enhancing the hydrophobicity of the surface reduced the friction coefficient; this agrees with the results presented in Figure 5(f).
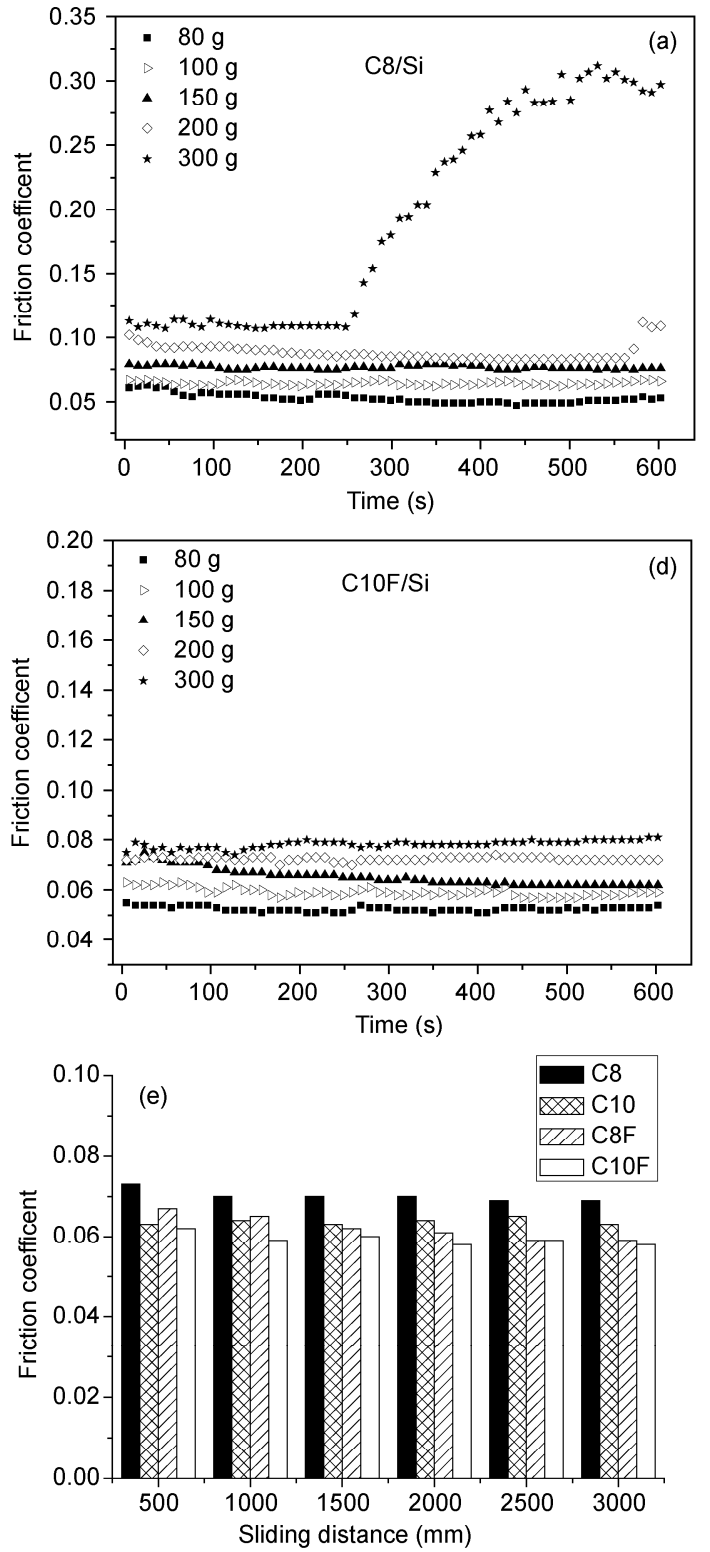

\section{Conclusions}

In summary, we successfully fabricated four kinds of alkylsilane SAM films on Si substrates and systematically studied their tribological properties, including the influence of sliding velocity and normal load under conditions of aqueous lubrication. With respect to wettability, the effects of the surface morphologies at the micro- and nano-scales and the variations in chemical composition at the surface, for fluorinated and non-fluorinated alkylsilanes, were discussed. We obtained relatively low friction coefficients for high sliding-velocities or normal loads using SAM films of fluorinated alkylsilanes on $\mathrm{Si}$ substrates. The conclusions drawn from these results will help us to design systems, using chemical methods, with improved frictional properties.
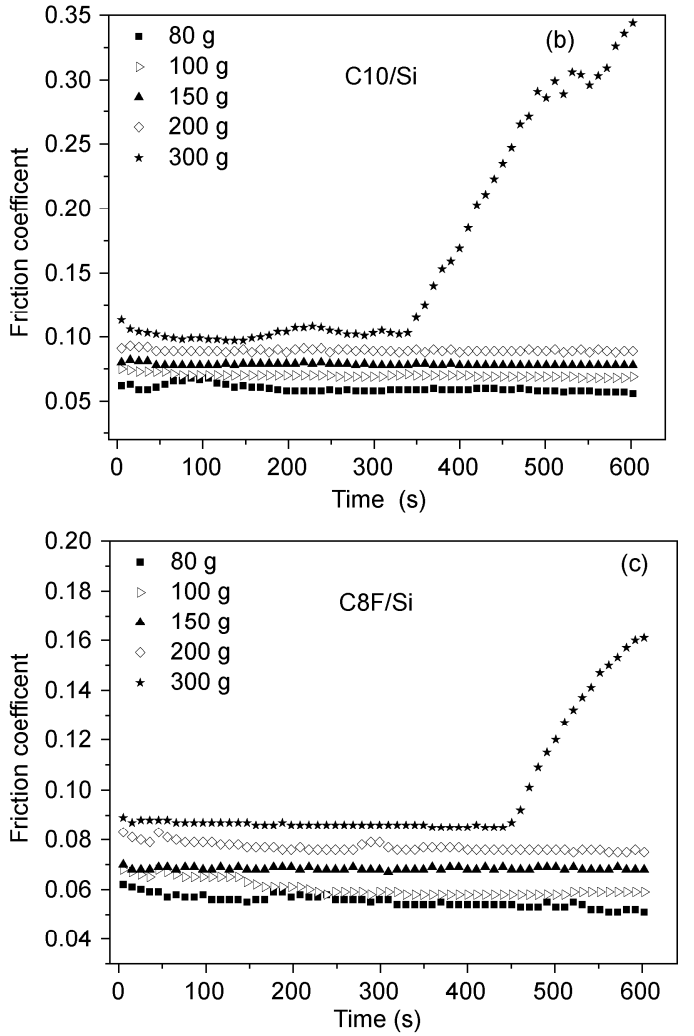

Figure 5 Variations in the friction coefficients over time at a sliding velocity of $10 \mathrm{~mm} / \mathrm{s}$ when a steel ball slides against (a) $\mathrm{C} 8 / \mathrm{Si}$, (b) $\mathrm{C} 10 / \mathrm{Si}$, (c) $\mathrm{C} 8 \mathrm{~F} / \mathrm{Si}$, (d) $\mathrm{C} 10 \mathrm{~F} / \mathrm{Si}$, and (e) $\mathrm{C} 8 / \mathrm{Si}, \mathrm{C} 10 / \mathrm{Si}, \mathrm{C} 8 \mathrm{~F} / \mathrm{Si}, \mathrm{C} 10 \mathrm{~F} / \mathrm{Si}$ at load of $100 \mathrm{~g}$ under water lubrication conditions. 
Such low-friction systems have potential applications in MEMS/NEMS and microfluidic devices.

The authors thank the National Natural Science Foundation of China (50805086, 50730007) and the Foundation for Innovative Research Groups of the National Natural Science Foundation of China (51021064).

1 Zhao Y P, Wang L S, Yu T S. Mechanics of adhesion in MEMS-A review. J Adhes Sci Technol, 2003, 17: 519-546

2 Komvopoulos K. Adhesion and friction forces in micro-electromechanical systems: Mechanisms, measurement, surface modification techniques, and adhesion theory. J Adhes Sci Technol, 2003, 17: 477-517

3 Maboudian R, Carraro C. Surface chemistry and tribology of MEMS. Annu Rev Phys Chem, 2004, 55: 35-54

4 Lorenz C D, Chandross M, Grest G S, et al. Tribological properties of alkylsilane self-assembled monolayers. Langmuir, 2005, 21: 1174411748

5 Spearing S M. Materials issues in microelectromechanical systems (MEMS). Acta Mater, 2000, 48: 179-196

6 Maboudian R. Surface processes in MEMS technology. Surf Sci Rep, 1998, 30: 209-270

7 Ding J N, Xie G X, Fan Z, et al. Microstructure and mechanical properties of heat-treated GeSb2Te4 thin films. J Wuhan Univ Technol, 2007, 22: 196-200

8 Bhushan B. Adhesion and stiction: Mechanisms, measurement techniques, and methods for reduction. J Vac Sci Technol B, 2003, 21: 2262-2296

9 Satyanarayana N, Sinha S K. Tribology of PFPE overcoated selfassembled monolayers deposited on Si surface. J Phys D: Appl Phys, 2005, 38: 3512-3522

10 Perry S S, Somorjai G A, Mate C M, et al. Role of defcts in compression and friction of anchored hydrocarbon chains on diamond. Tribol Lett, 1995, 1: 233-246

11 Mate C M, Novotny V J. Molecular-conormation and disjoining pressure of polymeric liquid-films. J Chem Phys, 1991, 94: 84208427

12 Vurens G H, Mate C M. The thermal stability of perfluoropolyethers on carbon surfaces. Appl Surf Sci, 1992, 59: 281-287

13 Takahara A, Kojio K, Kajiyama T. Effect of aggregation state on nanotribological behaviors of organosilane monolayers. Ultramicroscopy, 2002, 91: 203-210

14 Shuang L, Cao P, Colorado R, et al. Local packing environment strongly influences the frictional properties of mixed $\mathrm{CH}_{3}-$ and
$\mathrm{CF}_{3}$-terminated alkanethiol SAMs on Au(111). Langmuir, 2005, 21: 933-936

15 Bhushan B, Kulkarni A V, Koinkar V N, et al. Microtribological characterization of self-assembled and Langmuir-Blodgett monolayers by atomic and friction force microscopy. Langmuir, 1995, 11: 3189-3198

16 Tsukruk V V. Molecular lubricants and glues for micro- and nanodevices. Adv Mater, 2001, 13: 95-108

17 Rye R R, Nelson G C, Dugger M T. Mechanistic aspects of alkylchlorosilane coupling reactions. Langmuir, 1997, 13: 2965-2972

18 Deng K, Collins R J, Mehregany M, et al. Performance impact of monolayer coating of polysilicon micromotors. J Electrochem Soc, 1995, 142: 1278-1285

19 Sang Y, Dube M, Grant M. Dependence of friction on roughness, velocity, and temperature. Phys Rev E, 2008, 77: 036123

20 Li Q Y, Kim K S. Micromechanics of friction: Effects of nanometre-scale roughness. Proc Roy Soc A, 2008, 464: 1319-1343

21 Hammerstrom L, Jacobson S. Designed high-friction surfaces influence of roughness and deformation of the counter surface. Wear, 2008, 264: 807-814

22 Lorenz C D, Chandross M, Great G S, et al. Tribological properties of alkylsilane self-assembled monolayers. Langmuir, 2005, 21: 1174411748

23 Wang X K, Liu Y H, Luo J B, et al. A comparative study of the tribological properties between perfluoro and non-perfluoro alkylsilane self-assembled monolayers (SAMs). J Wuhan Univ technol, 2009, 24: 588-593

24 Liu Y H, Wang X K, Luo J B. et al. Fabrication and tribological properties of super-hydropgobic surface based on porous silicon. App Sur Sci, 2009, 255: 9430-9438

25 Huang C, Katz H E, West J E. Solution-processed organic field-effect transistors and unipolar inverters using self-assembled interface dipoles on gate dielectrics. Langmuir, 2007, 23: 13223-13231

26 Peisert H, Knupfer M, Schwieger T, et al. Fluorination of copper phthalocyanines: Electronic structure and interface properties. J Appl Phys, 2003, 93: 9683-9692

27 Fukushima H, Seki S, Nishikawa T, et al. Microstructure, wettability, and thermal stability of semifluorinated self-assembled monolayers (SAMs) on gold. J Phys Chem B, 2000, 104: 7417-7423

28 Tsukruk V V, Everson M P, Lander L M, et al. Nanotribological properties of composite molecular films: C60 anchored to a selfassembled. Langmuir, 1996, 12: 3905-3911

29 Guo L Y, Zhao Y P. Effect of chain length of self-assembled monolayers on adhesion force measurement by AFM. J Adhes Sci Technol, 2006, 20: 1281-1293

Open Access This article is distributed under the terms of the Creative Commons Attribution License which permits any use, distribution, and reproduction in any medium, provided the original author(s) and source are credited. 